\title{
A Novel Cytoskeletal Action of Xylosides
}

Caitlin P. Mencio ${ }^{1, \# a}$, Sharada Tilve1, Masato Suzuki², Kyohei Higashi², Yasuhiro

${ }^{1}$ Laboratory of Developmental Neurobiology, National Heart, Lung, and Blood Institute,

${ }^{2}$ Faculty of Pharmaceutical Sciences, Tokyo University of Science, Noda City, Chiba, Japan

\#a Current address: Schubot Center for Avian Health, Department of Veterinary 
Mencio, et al.

\section{Abstract}

Proteoglycan glycosaminoglycan (GAG) chains are attached to a serine residue in the

24 protein through a linkage series of sugars, the first of which is xylose. Xylosides are chemicals

25 which compete with the xylose at the enzyme xylosyl transferase to prevent the attachment of

26 GAG chains to proteins. These compounds have been employed at concentrations in the

27 millimolar range as tools to study the role of GAG chains in proteoglycan function. In the course

28 of our studies with xylosides, we conducted a dose-response curve for xyloside actions on

29 neural cells. To our surprise, we found that concentrations of xylosides in the nanomolar to

30 micromolar range had major effects on cell morphology. These effects are due to changes in

31 cytoskeletal dynamics. Concentrations of xylosides which were effective in altering morphology

32 did not alter GAG chain synthesis rates, nor did they produce any changes in gene expression

33 as determined by RNAseq of treated cells. These observations support a novel action of

34 xylosides on neuronal cells. 
Mencio, et al.

\section{Introduction}

Proteoglycans (PGs) are found in every tissue in the body. Consisting of two major components, a core protein and glycosaminoglycan (GAG) chain(s), they are essential components of the extracellular matrix. There are three major classes, differentiated by their GAG chain composition: heparan sulfate, chondroitin sulfate and keratan sulfate. PGs are involved in many important biological processes (1), especially in the central nervous system, where they regulate neuronal migration, axon guidance and differentiation $(2,3)$. They are also believed to play critical roles in neural de- and re-generation (4).

In the recent past, it has become more apparent that the physiological effects of proteoglycans can be attributed to their GAG chains. Moreover, the wide range of biological function is often attributed to the complexity and diversity of GAG chain modifications, sulfation being the most common. Altering GAG sulfation patterns has been known to change GAG chain receptor binding resulting in modified cell signaling (5-7).

GAG chain biosynthesis is a non-template driven process that begins for all PGs with a common linkage of three sugars (Xyl-Gal-Gal) to a serine on the core protein. The three classes then diverge with addition of disaccharides to the linkage region. For HS, these would be GIcNAc and GIcA, for CS the disaccharides are GalNAc and GIcA, and for KS they are GlcNAc and Gal. Each disaccharide in the chain may undergo several different modifications, primarily sulfation. The impact that modifications to the GAG chains has on neural development as well as other cellular processes remains an active area of research.

One major approach to understanding the function of GAG chains in PGs has been through the use of chemical modulators of GAG biosynthesis called xylosides which serve as competitive molecules for cellular sugar chain synthesis. Xyloside induced interference in GAG biosynthesis can lead to changes in GAG concentration, chain type, sulfation pattern, and molecular weight (8-10) as well as biological activity (11-13). Historically, xyloside research has utilized high (millimolar) concentrations that serve to primarily block endogenous GAG 
Mencio, et al.

61 production $(14,15)$. Relatively few studies used lower than mM concentrations (16). We

62 therefore conducted a dose-response study to determine the minimal concentration of xyloside

63 that would disrupt GAG chain synthesis in hippocampal pyramidal neurons and Neuro2A cells.

64 To our surprise, we saw major changes in cell morphology when cells were treated with

65 nanomolar xyloside concentrations but not micro- or millimolar treatment. After documenting

66 the cytoskeletal changes, we determined that nanomolar treatment of cells with xyoside will alter

67 sugar profiles with distinct differences found in heparan sulfate (HS) disaccharide composition

68 from both control cells and cells treated with the high concentration of xyloside. This study

69 serves as a first step in our attempt to understand how minor shifts in GAG chain composition or

70 concentration can affect biological processes and continues to support the critical role of sugars

71 in development and cellular function.

73 Materials and Methods

74 Laboratory animals

75 Experiments and procedures were performed in accordance with Institutional Animal Care and

76 Use Committee (IACUC) at the National Institutes of Health approved protocols. Pregnant

77 female C57BI/6 mice (Charles River) were housed in a pathogen free facility with standard $12 \mathrm{~h}$

78 light/dark cycle and unlimited access to food and embryonic (E17-19) pups where utilized for

79 embryonic hippocampal neuron primary cultures.

80 Cell culture

81 Primary hippocampal neuron cultures were prepared from embryonic (E17-19) C57BI/6 mouse

82 brains. Hippocampi were dissected and dissociated into single cell suspensions. Dissociated

83 cells were seeded onto coverslips coated with poly-L-lysine and cultured in $500 \mu \mathrm{L}$ Neurobasal

84 medium containing B27 supplement (Thermo Fisher) and $24 \mathrm{mM} \mathrm{KCl}$ at a density of 8-10k

85 cells/well to allow for observation of isolated neurons. After allowing $2 \mathrm{hr}$ for neuronal

86 attachment, media was replaced with $1 \mathrm{ml}$ fresh Neurobasal media containing DMSO, 500nM 
Mencio, et al.

87 xyloside, or $1 \mathrm{mM}$ xyloside. Cells were incubated for $72 \mathrm{hr}$ at $37^{\circ} \mathrm{C}$ and $5 \% \mathrm{CO} 2$ atmosphere and

88 then fixed and stained for DAPI, ßIII-tubulin, and actin (Phalloidin).

Neuro2A (ATCC) cells were cultured in DMEM media containing 10\% fetal bovine serum

(FBS) at $37^{\circ} \mathrm{C}$ with $5 \% \mathrm{CO}_{2}$. Cells were seeded onto coverslips, $35 \mathrm{~mm}$ glass bottom dishes

91 (MatTek), 6-well plates or T-75 (Corning) flasks depending on experimental design.

92 For conditioned media, Neuro2A cells were grown to about 50\% confluency in T-75 flasks

93 (Corning) in DMEM supplemented with 10\% FBS. At this point, DMEM containing FBS was

94 removed and cells were washed thrice with sterile PBS and then kept in DMEM only overnight.

95 The next day the media was replaced with media containing DMSO, 500nM xyloside or $1 \mathrm{mM}$

96 xyloside and cells were allowed to grow for $48 \mathrm{~h}$ at normal cell culture conditions. At this time,

97 media was removed and placed into $15 \mathrm{ml}$ conical tubes and spun for $10 \mathrm{~m}$ at 500 rpm to remove

98 floating cells and debris. The supernatant was transferred into a fresh tube and utilized for GAG

99 analysis.

102 Conditioned media was harvested from Neuro2A cells that had been serum starved overnight

103 and then treated for $48 \mathrm{~h}$ with xylosides in DMEM culture medium. Approximately $10 \mathrm{ml}$ of

104 conditioned media was collected from each experimental condition: DMOS, 500nM and 1mM

105 xyloside. This media was spun for $5 \mathrm{~min}$ at $2000 \mathrm{rpm}$ to remove cell debris and then transferred

106 to a new conical tube and frozen until analysis.

107 GAG extraction was performed as follows. The media (1 mL) was treated with $10 \%$ TCA

108 and centrifuged at 12000 rpm for 5 min to remove proteins. GAGs were collected by Amicon

109 Ultra Centrifugal Filter 3K device (Merck Millipore, Billerica, MA, USA) and suspended with 100

$110 \mu \mathrm{L}$ of $\mathrm{H}_{2} \mathrm{O}$. Fifty $\mu \mathrm{L}$ of $\mathrm{GAG}$ s solution was moved to new $1.5 \mathrm{~mL}$ microcentrifuge tube and

111 lyophilized. Resulting GAG samples were incubated in the reaction mixture $(35 \mu \mathrm{L})$ containing 
Mencio, et al.

$11228.6 \mathrm{mM}$ Tris-acetate $(\mathrm{pH} 8.0)$ and $50 \mathrm{mIU}$ of chondroitinase $\mathrm{ABC}$ for $16 \mathrm{~h}$ at $37^{\circ} \mathrm{C}$.

113 Depolymerized samples were boiled and evaporated, unsaturated disaccharides of CS were

114 collected by Amicon Ultra Centrifugal Filter 30K device (Merck Millipore, Billerica, MA, USA).

115 The remaining HS samples in filters of spin columns were transferred to new microtubes and

116 incubated in $16 \mu \mathrm{L}$ of reaction mixture $(\mathrm{pH} 7.0)$, containing $1 \mathrm{mU}$ heparinase I (Seikagaku Corp.,

117 Tokyo, Japan), $1 \mathrm{mU}$ heparinase II (Iduron, Manchester, UK), $1 \mathrm{mU}$ heparinase III (Seikagaku

118 Corp., Tokyo, Japan), $31.3 \mathrm{mM}$ sodium acetate, and $3.13 \mathrm{mM}$ calcium acetate for $16 \mathrm{~h}$ at $37^{\circ} \mathrm{C}$.

119 Unsaturated disaccharide analysis using reversed phase ion-pair chromatography with sensitive

120 and specific post-column detection was performed as described previously (17). Disaccharide

121 composition analysis of CS or HS was performed by reversed phase ion-pairing

122 chromatography with sensitive and specific post-column detection. A gradient was applied at a

123 flow rate of $1.0 \mathrm{ml} \mathrm{min}{ }^{-1}$ on Senshu Pak Docosil $(4.6 \times 150 \mathrm{~mm}$; Senshu Scientific Co., Ltd.,

124 Tokyo, Japan) at $60^{\circ} \mathrm{C}$. The eluent buffers were as follows: $\mathrm{A}, 10 \mathrm{mM}$ tetra- $n$-butylammonium

125 hydrogen sulfate in $12 \%$ methanol; $\mathrm{B}, 0.2 \mathrm{M} \mathrm{NaCl}$ in buffer $\mathrm{A}$. The gradient program of CS

126 disaccharides analysis was as follows: 0-10 $\min (1 \% \mathrm{~B}), 10-11 \mathrm{~min}(1-10 \% \mathrm{~B}), 11-30 \mathrm{~min}(10 \%$

127 B), $30-35 \mathrm{~min}(10-60 \% \mathrm{~B})$, and $35-40 \mathrm{~min}(60 \% \mathrm{~B})$. The gradient program of HS disaccharides

128 analysis was as follows: 0-10 $\min (1-4 \% \mathrm{~B}), 10-11 \min (4-15 \% \mathrm{~B}), 11-20 \mathrm{~min}(15-25 \% \mathrm{~B}), 20-22$

$129 \min (25-53 \% \mathrm{~B})$, and $22-29 \min (53 \% \mathrm{~B})$. Aqueous $(0.5 \%(\mathrm{w} / \mathrm{v}))$ 2-cyanoacetamide solution and

$1301 \mathrm{M} \mathrm{NaOH}$ were added to the eluent at the same flow rates $\left(0.25 \mathrm{ml} \mathrm{min}^{-1}\right)$ by using a double

131 plunger pump. The effluent was monitored fluorometrically (Ex., $346 \mathrm{~nm}$; Em., $410 \mathrm{~nm}$ ).

132 Expression levels of HS or CS were expressed as total amounts of unsaturated disaccharides.

134 Microscopy and Image Processing

135 Cells were imaged using a Nikon A1R or Zeiss 880 confocal microscope with 60X and 63X

136 objectives depending on experiment. Z-stacks were maximally projected onto a single plane

137 using Zeiss or ImageJ image processing software. Fixed cell imaging: For images used in 
Mencio, et al.

138 fluorescence quantification, image capture settings were held constant, and samples from within

139 each group were imaged at the same time. Fluorescence intensity was measured using ImageJ,

140 with identical settings for all samples within each analysis.

142 Neurite outgrowth and growth cone analysis

143 After fixation and staining, at least 60 images were taken across two coverslips per condition.

144 Files were analyzed by an experimenter blinded to the experimental conditions. Neurons were

145 measured if they were isolated from other neurons and had distinct nuclei and at least one

146 neurite longer than the diameter of the cell body. Both longest and total neurite measurements

147 were obtained for each neuron and at least 60 neurons were measured for each condition.

148 Growth cone measurements were conducted by tracing the end of the neurite from the point it

149 widened from its average diameter of the stalk and where phalloidin staining began to show

150 more intense and spiked appearance as is common with growing ends of neurites. Only the

151 largest growth cone of the neuron was measured. Each experiment was performed in triplicate.

EB3 comet analysis: Neuro2A cells were grown in culture until about $30 \%$ confluent.

155 Cells were then treated with DMSO, 500nM xyloside or $1 \mathrm{mM}$ xyloside for $48 \mathrm{~h}$. $24 \mathrm{~h}$ into the

156 incubation, cells were transfected with EB3-GFP using Avalanche®-Omni transfection reagent.

157 The next day, cells were imaged on the Nikon A1R with a 60x oil objective. Transfected cells

158 were imaged every $12.5 \mathrm{sec}$ over $5 \mathrm{~min}$. Images were then processed using u-track software

159 (18) and comets assessed for speed, lifetime and length.

160 Actin bundle analysis: Neuro2A cells were grown in culture until about $30 \%$ confluent.

161 Cells were then treated with DMSO, 500nM xyloside or $1 \mathrm{mM}$ xyloside for $48 \mathrm{~h}$. $24 \mathrm{~h}$ into the

162 incubation, cells were transfected with Ftractin-mCherry using Avalanche®-Omni transfection

163 reagent. The next day, cells were imaged on the Zeiss 880 confocal microscope with $63 \mathrm{X}$ 
Mencio, et al.

164 objectives. Transfected cells with lamellipodia were imaged in a z-stack. In FIJl, z-stacks were

165 max projected and a line drawn through the lamellipodia and a line scan performed based upon

166 fluorescence. Actin bundles were identified as peaks of increased fluorescence. Bundles were

167 counted and the area under the curve taken to compare quantity and size of the bundles.

169 RNA-seq

170 Between 6-15 micrograms per sample of total RNA from three samples each of Neuro2A cells

171 treated with either DMSO, LCX or HCX were sequenced by Illumina at Omega Bioservices

172 (Norcross, GA). Data analysis was performed using the Partek Flow statistical analysis software

173 (Partek Incorporated). For this, raw data from three replicates of the three conditions were

174 imported to Partek Flow for alignment and quality controls. Aligned reads were quantified to

175 transcriptome, filtered out on low expression and normalized. Feature gene lists with at least a

176 two-fold change in gene expression with a $\mathrm{P}<0.05$ were created by pairwise comparison.

177 Pseudogenes were eliminated from the final list of altered genes and the list plotted as a

178 heatmap. In order to visualize the difference of the expression between DMSO, LCX and HCX,

179 the data were centered by subtracting the mean of the log2 Fold Change of all samples for each

180 gene from the original log2 Fold Change value. The centered data of all samples were then

181 plotted into a heat map The rows of the heatmaps (genes) were ordered by foldchange (19).

183 Statistics

184 All statistical tests were performed using GraphPad Prism 7.0 (GraphPad Software, La Jolla,

185 CA). Neurite lengths in culture were compared using Kruskal-Wallis Analysis of Variance and 186 Mann-Whitney U tests. 
Mencio, et al.

We sought to evaluate the effects of inhibition of GAG chain synthesis on hippocampal neurons in culture. A previous study noted that concentrations of 0.1 and $0.2 \mathrm{mM}$ xyloside

191 perturbed the generation of neuronal polarity (20), but we sought to determine a more complete

192 dose-response curve. We therefore added 4-methyl-umbelliferyl- $\beta$-D-xylopyranoside (4-MU) in

193 a range of $0.5 \mathrm{nM}$ to $1 \mathrm{mM}$ to the medium of dissociated embryonic hippocampal neurons, and

194 fixed and stained cultured after $72 \mathrm{~h}$. We observed a surprising dose-dependent response to 4-

195 MU: neurons treated with lower concentrations showed enlarged growth cones that exhibited

196 looped microtubules as compared to DMSO treated cultures or cultures treated with mM

197 concentrations (Fig. 1, Supp. Fig. 1). Fig. 1A shows representative images taken from the range

198 of concentrations: DMSO (control), $500 \mathrm{nM} \mathrm{4-MU}$ as the low xyloside concentration (LCX) and 1

$199 \mathrm{mM}$ MU as the high xyloside concentration (HCX). As presented in Fig. 1B, there was a

200 difference in growth cone size with the different treatments: neurons treated with LCX had

201 significantly larger growth cones than those treated with DMSO or HCX. To determine if the

202 enlarged growth cones was due to neurite stalling, the length of the longest neurite was

203 measured for each neuron in the condition. There was no significant difference in neurite length

204 between all conditions (Fig. 1C). The lower end of the dose-response curve is presented in

205 Supp. Fig. 1.

As primary neuron culture is often limiting in cell number, we decided to assess if the

207 mouse neural crest-derived cell line Neuro2a (N2A) would show similar morphological changes

208 and could be used to study any structural or biochemical changes between HCX and LCX

209 treatment. Observation of the cytoskeleton and overall cellular morphology in LCX treated N2A

210 cells shows that these cells exhibit actin-rich lamellipodia that were not observed in N2A cells

211 treated with either DMSO or HCX (Supp. Fig. 2). With a confirmed change in cytoskeleton and

212 for the sake of uniformity and economy, we decided to utilize N2A cells for all other experiments

213 in this study. 
Mencio, et al.

\section{LCX treatment reduces cellular movement}

After observing changes in morphology, we next wanted to check if these changes alter the cells ability to migrate. N2A cells were treated with DMSO, LCX or HCX for $48 \mathrm{~h}$ at which point cells were imaged using brightfield microscopy for $4 \mathrm{~h}$ with images being taken every 8-10 min (Fig. 2). Cells within the image were tracked and velocity and total distance was calculated.

There was a significant reduction in both velocity and total distance in LCX treated cells as compared to DMSO and HCX treated N2As (Fig. 2B). This reduction in movement implicates possible changes in cytoskeleton dynamics.

\section{LCX treatment affects both actin and microtubule dynamics}

To determine if altered cytoskeleton may plan a role in LCX induced changes in morphology and migration, we next assessed both actin and microtubules in N2A cells. N2A cells were transfected with Ftractin-mCherry and treated for 48h with DMSO, LCX or HCX. At 48h, visual observation showed a marked difference in lamellipodia of LCX treated cells as compared to DMSO and HCX treated N2As. DMSO and HCX-treated cells showed bright and thick actin bundles while LCX treated cells appeared to have fewer bundles which also appeared thinner than their control counterparts (Fig. 3A). We quantified both the area and number of actin bundles from these images. LCX treated N2A cells exhibited lamellipodia that had significantly fewer actin bundles per $10 \mu \mathrm{m}$ when compared to controls (Fig. 3B).

Additionally, the area under the curve for these bundles was significantly reduced in LCX treated cells as compared to DMSO or HCX treated N2As (Figure $2 \mathrm{C}$ ) indicating less robust actin bundles in LCX lamellipodia.

With a measured effect on actin, we next wanted to assess if microtubules, the other major cytoskeleton element, were also affected. To examine microtubule dynamics, EB3-GFP transfected N2A cells were treated for 48h with DMSO, LCX or HCX. EB3-GFP cells were imaged at $60 \mathrm{x}$ with one image taken every $12.5 \mathrm{sec}$ for $5 \mathrm{~min}$ (Fig. 4A). Images were used to 
241 measure speed, persistence and lifetime. Both LCX and HCX treated N2A cells exhibited a

242 higher percentage of faster moving EB3 comets as compared to controls (Fig. 4B, left).

243 Additionally, xyloside treatment resulted in longer persistence of EB3 comets compared to

244 DMSO treated N2As (Fig. 4B, center). There were no significant changes in comet lifetime

245 between all conditions (Fig. 4B, right). These results, taken together with the effects on actin

246 bundling, suggest LCX treatment alters cytoskeleton dynamics which lead to changes in cellular

247 morphology and movement.

LCX treatment alters GAG chain but not mRNA profile

Xylosides have been known to affect cellular GAG chains, both increasing the rate of

251 synthesis and secretion (21) and composition (22). These GAG chains have been linked to

252 cellular signaling that could lead to altered cytoskeleton. To determine if LCX treatment affects

253 GAG chain production or sulfation, N2A cells were treated with DMSO, LCX, or HCX in serum

254 free media for $48 \mathrm{~h}$. Conditioned media were collected and GAG chains analyzed for

255 concentration and disaccharide composition. As previously reported, there was a dose

256 dependent increase in GAG chain accumulation with xyloside treatment. Both LCX and HCX

257 increased CS chain concentration as compared to control. Notably, HCX caused a much larger

258 increase that was significantly different from LCX (Fig. 5A).

259 Disaccharide composition showed that conditioned media from DMSO treated cells

260 contained a close to even split between non-sulfated and 4-sulfated chondroitin sulfate GAG

261 chains. Xyloside treatment, both LCX and HCX, lead to an increase in 4-sulfated CS GAG (Fig,

262 5B). However, both LCX and HCX showed the same change while the changes in morphology

263 and cytoskeleton were quite different. This could be due to changes in HS GAG chains, the

264 next most abundant sugar chain that is often involved in receptor binding.

265 The HS chains found in the conditioned media were also assessed. In contrast to CS,

266 only HCX treatment led to a significant increase in HS as compared to DMSO and LCX. There 
bioRxiv preprint doi: https://doi.org/10.1101/2022.01.31.478500; this version posted January 31,2022. The copyright holder for this preprint

(which was not certified by peer review) is the author/funder. This article is a US Government work. It is not subject to copyright under 17 USC 105 and is also made available for use under a CCO license.

Mencio, et al.

267 was no difference between HS concentration of DMSO and LCX (Fig. 5C). However, upon

268 examination of the disaccharide composition, it was found that all three treatment groups had

269 different disaccharide profiles. Conditioned media from DMSO treated cells showed mostly

270 non-sulfated disaccharides with a small percentage of $\mathrm{N}$-sulfated and even smaller group of 6-

271 sulfated disaccharides (Fig. 5D). In contrast, LCX treatment resulted in an increase in N-

272 sulfated disaccharides while HCX treatment led to a larger increase in N-sulfation, loss of 6-

273 sulfation and the presence of a small amount of 2-sulfated, N-sulfated disaccharides (Fig. 4D).

274 These findings indicate that xyloside treatment can change GAG chain synthesis and

275 composition, and alterations to HS appear to occur in a concentration dependent manner.

276 To rule out the possibility that changes in cytoskeleton observed may be due to LCX

277 treatment altering transcription and thus protein levels, we next performed RNA-seq to

278 determine which, if any, proteins displayed altered mRNA production. Cultures of Neuro2A cells

279 were treated with DMSO, LCX and HCX and RNA was extracted after 48 hours and

280 pyrosequenced. The raw data were filtered using Partek Flow as noted in materials and

281 methods. The filtered counts were then used to determine those genes whose expression was

282 altered by $>2 X$ and statistically significant using $p<0.05$ FDR. Using these criteria, we found no

283 genes whose change in expression was different between LCX and DMSO, while we did find

284 changes in gene expression when comparing HCX with both DMSO and LCX. Fig. 6A presents

285 volcano plots which indicate the differentially expressed genes between HCX and DMSO and

286 HCX and LCX. Fig. 6B presents a Venn diagram that indicates the number of genes changed in

287 each condition. Interestingly, majority of genes whose expression was changed were

288 downregulated by exposure to xylosides (Fig. 6B). The Venn diagram also indicates that only

289 about $1 / 3$ of the genes were differentially expressed by both HCX vs DMSO and HCX vs LCX.

290 Fig. 6C presents a heat map of the level of expression of those genes which are known to be

291 translated into protein as compared to the average level over all conditions. There was no 
Mencio, et al.

292 preference in in specific pathways using GO terms. Thus, the changes in cytoskeletal dynamics

293 due to LCX cannot be due to changes in gene expression.

\section{Discussion}

Xylosides have been used in research as a GAG-biosynthesis inhibitor since the 1970s

297 (14), and continue to be used today. Virtually all published work has used these small

298 molecules in the millimolar range as originally published by Schwartz et al. (21). Our work

299 reveals a novel action of xylosides on cell morphology that occurs at sub-micromolar

300 concentrations, well below any previously reported to be active. Interestingly, LCX treatment

301 only slightly raised the secretion of CS and HS into the medium, a major effect of these

302 compounds when used in culture. Moreover, we could not identify any changes in gene

303 expression in cells exposed to 4-MU.

Several studies have investigated dose-response curves with xylosides GAG chain

305 production on at concentrations in the micromolar range. Carrino and Caplan (10) found

306 increased incorporation of ${ }^{35} \mathrm{~S}$ into the medium of chick muscle cultures with concentrations

307 down to $1 \mathrm{C}$. Interestingly, this concentration had minimal effect on the structure of CS GAG

308 chains, while mM concentrations significantly altered structure. Similarly, Weinstein, et al. (23)

309 found increased ${ }^{35} \mathrm{~S}$ secretion into the medium by human chondrocytes treated with $25 \mu \mathrm{M}$

310 xylosides, with a maximum attained at $100 \mu \mathrm{M}$. More recently, Persson, et al. (22),

311 systematically looked at GAG chain synthesis and composition influenced by (D)2-naphthyl $\beta$-D-

312 xylopyranoside (XyINap) in several different cell lines. Consistent with other observations, they

313 found an increase in GAG production with $10 \mu \mathrm{M}$ XylNap, peaking at $100 \mu \mathrm{M}$. They also found

314 both concentration and cell-type changes in HS and CS. These results are consistent with our

315 findings that treatment with concentrations of 4-MU lower than $1 \mu \mathrm{M}$ did not alter GAG chain

316 production. 
Mencio, et al.

The major change we found with low concentration of 4-MU were in the cytoskeleton.

318 Several previous studies have examined the effect of high concentrations of xylosides on

319 cytoskeleton. Adding $1 \mathrm{mM}$ xyloside to vascular smooth muscle cells lead to a reduction in the

320 number of $\alpha$-actin containing cytoskeletal filaments $(24,25)$. Treatment with $2 \mathrm{mM}$ xyloside

321 treatment impeded tubule formation during nematocyst development, implicating CS in the

322 stabilization of membrane protrusions (26). Several studies have found that inhibiting GAG

323 biosynthesis often leads to a reduction in invasion and migration, implicating the extracellular

324 matrix as a modulator for cytoskeletal organization or stability (27-29) In one of the few

325 research studies that utilized lower concentrations of xyloside, Mani et al. (30) showed that

326 treatment with micromolar xyloside inhibited cell proliferation, a cytoskeletal dependent process,

327 in a range of cell types. They also showed that this effect was cell type specific with 150-200

$328 \mu \mathrm{M}$ xyloside resulting in $50 \%$ inhibition of proliferation in human lung carcinoma, $50 \mu \mathrm{M}$ xyloside

329 treatment in transformed human umbilical vein endothelial cells, and no treatment effect in

330 human lung fibroblasts. Because these manipulations likely altered both HS and CS GAGs, the

331 question does arise as to whether these changes were due to alterations in growth factor

332 signaling.

333 Previous research in our lab as well as others has shown that neurons and neuronal cell

334 types are sensitive to GAG chains and changes in sulfation patterns (31-33). This sensitivity is

335 linked to several processes that are regulated by cytoskeletal rearrangements such as neural

336 migration, polarity and axon guidance. For example, degradation of GAG chains by enzyme or

337 disruption of biosynthesis by xylosides leads to altered neuronal migration (34). The addition of

338 HS and CS to embryonic rat neurons primarily resulted in neurons with a single long axon.

339 Conversely the addition of DS resulted in neurons with increased dendritic growth that

340 maintained higher levels of microtubule-associated protein 2 expression (35). In terms of axon

341 guidance, many studies have shown the bifunctionality of HS and CS as guidance cues. HS is

342 commonly associated with permissive substrates while CS, especially 4-sulfated CS, is seen as 
Mencio, et al.

343 inhibitory (36). Proteins that have been implicated in axon guidance such as Sema5A and

344 RPTPo have been shown to interact with both CS and HS at binding sites unique to the type of

345 GAG chain $(7,37)$. As both Sema5A and RPTPo have been shown to influence cytoskeletal

346 signaling pathways, it would not be a leap to associate GAG binding with changes in the neural

347 cytoskeleton. The changes in morphology we observed would support the idea that altering

348 GAGs could result in aberrant signaling which may affect neuronal cytoskeleton. Additionally,

349 our results suggest that the difference in changes present between low and high concentration

350 xyloside treatment may lean toward subtle changes in GAG chains having more distinct

351 biological effects. This is an area of research that needs further exploration.

352 Because the morphological changes in neurons take several days to develop, we tested

353 the hypothesis that there would be changes in gene expression. However, our RNAseq

354 analysis did not find any RNAs whose level was significantly changed by exposure to LCX as

355 compared to the control situation. However, we did find a subset of genes whose expression

356 was significantly increased by HCX over either control or LCX. A large group of these code for

357 proteins in the extracellular matrix, including Tenascin-C, Collagen 14, MMP9 and astrotactin 2,

358 while another group, including a-actin, advillin, protein tyrosine phosphatase receptor type $\mathrm{T}$ and

$359 \mathrm{ABI}$ family member 3 are involved in controlling cytoskeletal dynamics. However, none of these

360 were changed at concentrations that produced the morphological changes. Treatment of HeLa

361 cells with $\mathrm{mM}$ xylosides caused the upregulation of several RNAs related to proteoglycan

362 synthesis (38), but we did not find any overlap with our results. Thus, it is not likely that the

363 changes we observe are due to changes in gene expression.

As low concentration xyloside treatment alters concentration and sulfation patterns of

365 both HS and CS GAG chains, it is possible that observed effects could be driven by multiple

366 pathways. These changes appear to be concentration specific. No visible effect is observed in

$3671 \mathrm{mM}$ xyloside treated neurons or neuro2A cells. This could imply that utilizing lower

368 concentrations that result in distinct, but subtle changes to GAG profiles may produce more 
Mencio, et al.

369 unique and useful biological outcomes. By not overwhelming the biosynthetic machinery,

370 nanomolar concentrations may provide differing GAG chains that can work with still present

371 endogenous GAG chains to support or inhibit GAG mediated receptor binding. As low

372 concentration xyloside treatment does not appear to alter transcription, we believe the next

373 steps are to focus on assessing any phosphorylation changes in signaling pathways linked to

374 cytoskeletal control. Further research is needed to determine the effects of LCX on intracellular

375 signaling pathways controlling cytoskeletal rearrangements.

376

377 Acknowledgements

$378 \quad$ Images in this manuscript were acquired in the Light Microscopy Core of the

379 Division of Intramural Research of the National Heart, Lung, and Blood Institute, NIH.

380 We greatly appreciate advice and assistance from Dr. Hiro Katagiri. 
Mencio, et al.

384 References

385

386 1. Wight TN, Kinsella MG, Qwarnstrom EE. The role of proteoglycans in cell adhesion,

387 migration and proliferation. Curr Opin Cell Biol. 1992;4(5):793-801.

$388 \quad 2 . \quad$ Maeda N. Proteoglycans and neuronal migration in the cerebral cortex during

389 development and disease. Front Neurosci. 2015;9:98.

$3903 . \quad$ Masu M. Proteoglycans and axon guidance: a new relationship between old partners. J

391 Neurochem. 2016;139 Suppl 2:58-75.

392 4. Bandtlow CE, Zimmermann DR. Proteoglycans in the developing brain: new conceptual

393 insights for old proteins. Physiol Rev. 2000;80(4):1267-90.

394 5. Salbach J, Kliemt S, Rauner M, Rachner TD, Goettsch C, Kalkhof S, et al. The effect of the

395 degree of sulfation of glycosaminoglycans on osteoclast function and signaling pathways.

396 Biomaterials. 2012;33(33):8418-29.

397 6. Miller GM, Hsieh-Wilson LC. Sugar-dependent modulation of neuronal development,

398 regeneration, and plasticity by chondroitin sulfate proteoglycans. Exp Neurol. 2015;274(Pt

399 B):115-25.

400 7. Katagiri Y, Morgan AA, Yu P, Bangayan NJ, Junka R, Geller HM. Identification of novel

401 binding sites for heparin in receptor protein-tyrosine phosphatase (RPTP ): Implications for

402 proteoglycan signaling. J Biol Chem. 2018;293(29):11639-47.

403 8. Schwartz NB, Domowicz MS. Proteoglycans in brain development and pathogenesis.

404 FEBS Lett. 2018;592(23):3791-805. 
Mencio, et al.

405 9. Fritz TA, Esko JD. Xyloside priming of glycosaminoglycan biosynthesis and inhibition of

406 proteoglycan assembly. Methods Mol Biol. 2001;171:317-23.

407 10. Carrino DA, Caplan Al. The effects of $\beta$-D-xyloside on the synthesis of proteoglycans by

408 skeletal muscle: lack of effect on decorin and differential polymerization of core protein-bound

409 and xyloside-linked chondroitin sulfate. Matrix Biol. 1994;14(2):121-33.

410 11. Smith-Thomas LC, Stevens J, Fok-Seang J, Faissner A, Rogers JH, Fawcett JW. Increased

411 axon regeneration in astrocytes grown in the presence of proteoglycan synthesis inhibitors. J

412 Cell Sci. 1995;108(Pt 3):1307-15.

413 12. Muto J, Naidu NN, Yamasaki K, Pineau N, Breton L, Gallo RL. Exogenous addition of a C-

414 xylopyranoside derivative stimulates keratinocyte dermatan sulfate synthesis and promotes

415 migration. PLoS One. 2011;6(10):e25480.

416 13. Raman K, Ninomiya M, Nguyen TK, Tsuzuki Y, Koketsu M, Kuberan B. Novel

417 glycosaminoglycan biosynthetic inhibitors affect tumor-associated angiogenesis. Biochem

418 Biophys Res Commun. 2011;404(1):86-9.

419 14. Schwartz NB. Regulation of chondroitin sulfate synthesis. Effect of $\beta$-xylosides on

420 synthesis of chondroitin sulfate proteoglycan, chondroitin sulfate chains, and core protein. J

421 Biol Chem. 1977;252(18):6316-21.

422 15. Okayama M, Kimata K, Suzuki S. The influence of $p$-nitrophenyl $\beta$ - $d$-xyloside on the

423 synthesis of proteochondroitin sulfate by slices of embryonic chick cartilage. J Biochem.

$424 \quad 1973 ; 74(5): 1069-73$.

425 16. Schwarz K, Breuer B, Kresse H. Biosynthesis and properties of a further member of the 426 small chondroitin/dermatan sulfate proteoglycan family. J Biol Chem. 1990;265(35):22023-8. 
Mencio, et al.

427 17. Imamura M, Higashi K, Yamaguchi K, Asakura K, Furihata T, Terui Y, et al. Polyamines

428 release the let-7b-mediated suppression of initiation codon recognition during the protein

429 synthesis of EXT2. Sci Rep. 2016;6:33549.

430 18. Roudot P, Legant WR, Zou Q, Dean KM, Welf ES, David AF, et al. u-track 3D: measuring

431 and interrogating intracellular dynamics in three dimensions. bioRxiv. 2020:2020.11.30.404814.

432 19. Zhu G, Mayer-Wagner S, Schroder C, Woiczinski M, Blum H, Lavagi I, et al. Comparing

433 effects of perfusion and hydrostatic pressure on gene profiles of human chondrocyte. J

434 Biotechnol. 2015;210:59-65.

435 20. Nishimura K, Ishii M, Kuraoka M, Kamimura K, Maeda N. Opposing functions of

436 chondroitin sulfate and heparan sulfate during early neuronal polarization. Neuroscience.

$437 \quad 2010 ; 169(4): 1535-47$.

438 21. Schwartz NB, Galligani L, Ho PL, Dorfman A. Stimulation of synthesis of free chondroitin

439 sulfate chains by $\beta$-D-xylosides in cultured cells. Proc Natl Acad Sci USA. 1974;71(10):4047-51.

440 22. Persson A, Ellervik U, Mani K. Fine-tuning the structure of glycosaminoglycans in living

441 cells using xylosides. Glycobiology. 2018;28(7):499-511.

442 23. Weinstein T, Evron Z, Trebicz-Geffen M, Aviv M, Robinson D, Kollander Y, et al. $\beta$-D-

443 xylosides stimulate GAG synthesis in chondrocyte cultures due to elevation of the extracellular

444 GAG domains, accompanied by the depletion of the intra-pericellular GAG pools, with

445 alterations in the GAG profiles. Connect Tissue Res. 20111207 ed2012. p. 169-79.

446 24. Hamati HF, Britton EL, Carey DJ. Inhibition of proteoglycan synthesis alters extracellular

447 matrix deposition, proliferation, and cytoskeletal organization of rat aortic smooth muscle cells

448 in culture. J Cell Biol. 1989;108(6):2495-505. 
Mencio, et al.

449 25. Carey DJ. Biological functions of proteoglycans: use of specific inhibitors of proteoglycan

450 synthesis. Mol Cell Biochem. 1991;104(1-2):21-8.

451 26. Adamczyk P, Zenkert C, Balasubramanian PG, Yamada S, Murakoshi S, Sugahara K, et al.

452 A non-sulfated chondroitin stabilizes membrane tubulation in cnidarian organelles. J Biol Chem.

$453 \quad 2010 ; 285(33): 25613-23$.

454 27. Faassen AE, Schrager JA, Klein DJ, Oegema TR, Couchman JR, McCarthy JB. A cell surface

455 chondroitin sulfate proteoglycan, immunologically related to CD44, is involved in type I

456 collagen-mediated melanoma cell motility and invasion. J Cell Biol. 1992;116(2):521-31.

457 28. Sutton A, Friand V, Brule-Donneger S, Chaigneau T, Ziol M, Sainte-Catherine O, et al.

458 Stromal cell-derived factor-1/chemokine (C-X-C motif) ligand 12 stimulates human hepatoma

459 cell growth, migration, and invasion. Mol Cancer Res. 2007;5(1):21-33.

460 29. Raman K, Kuberan B. Click-xylosides mitigate glioma cell invasion in vitro. Mol Biosyst.

$461 \quad 2010 ; 6(10): 1800-2$.

462 30. Mani K, Havsmark B, Persson S, Kaneda Y, Yamamoto H, Sakurai K, et al.

463 Heparan/chondroitin/dermatan sulfate primer 2-(6-hydroxynaphthyl)-O-beta-D-xylopyranoside

464 preferentially inhibits growth of transformed cells. Cancer Res. 1998;58(6):1099-104.

465 31. Lander C, Zhang H, Hockfield S. Neurons produce a neuronal cell surface-associated

466 chondroitin sulfate proteoglycan. J Neurosci. 1998;18(1):174-83.

467 32. Pearson CS, Mencio CP, Barber AC, Martin KR, Geller HM. Identification of a critical

468 sulfation in chondroitin that inhibits axonal regeneration. Elife. 2018;7.

469 33. Saied-Santiago K, Bülow HE. Diverse roles for glycosaminoglycans in neural patterning.

470 Dev Dyn. 2018;247(1):54-74. 
Mencio, et al.

471 34. Kubota Y, Morita T, Kusakabe M, Sakakura T, Ito K. Spatial and temporal changes in

472 chondroitin sulfate distribution in the sclerotome play an essential role in the formation of

473 migration patterns of mouse neural crest cells. Dev Dyn. 1999;214(1):55-65.

474 35. Lafont $F$, Rouget $M$, Triller A, Prochiantz A, Rousselet A. In vitro control of neuronal

475 polarity by glycosaminoglycans. Development. 1992;114:17-29.

476 36. Mutalik SP, Gupton SL. Glycosylation in Axonal Guidance. Int J Mol Sci. 2021;22(10).

477 37. Kantor DB, Chivatakarn O, Peer KL, Oster SF, Inatani M, Hansen MJ, et al. Semaphorin 5A

478 is a bifunctional axon guidance cue regulated by heparan and chondroitin sulfate

479 proteoglycans. Neuron. 2004;44(6):961-75.

480 38. Sasaki K, Komori R, Taniguchi M, Shimaoka A, Midori S, Yamamoto M, et al. PGSE is a

481 novel enhancer regulating the proteoglycan pathway of the mammalian golgi stress response.

482 Cell Struct Funct. 2019;44(1):1-19. 
Figure 1. Altered cytoskeleton seen in cells treated with 500nM (LCX) but not 1mM (HCX) xyloside. A) Example of a primary mouse hippocampal neuron treated for $72 \mathrm{~h}$ with DMSO,

487 LCX, or HCX. White arrow indicates enlarged growth cones in LCX treated neuron. B)

488 Quantification of growth cone area and length of longest neurite.in DMSO, LCX and HCX

489 treated neurons. LCX treated neurons have significantly increased growth cone area compared

490 to control or HCX conditions. Scale $=25 \mu \mathrm{m} .{ }^{* *} p<0.01$

491 Fig. 2. LCX reduces cell migration. Neuro2A cells were observed using time-lapse microscopy.

492 A) Representative images taken at the indicated intervals. Letters show positions of specific

493 cells. B) Dot plot of velocity of individual cells taken as distance moved in each frame. ${ }^{*} p<$

494 0.05. Scale $=25 \mu \mathrm{m}$

495 Figure 3. LCX alters actin bundling. A) Representative images of Neuro2A cells treated with

496 DMSO, LCX, or HCX, and fixed and stained with phalloidin. Insets show line scans of

497 fluorescence intensity across the lamellipodia of indicated cells. B) Plots of area under the

498 curve and the number of peaks for each of the three conditions. Scale $=10 \mu \mathrm{m} .{ }^{* \star} p<0.01$.

500 Figure 4. Xyloside treatment alters microtubule dynamics. A) Images of living Neuro2A cells 501 (top) expressing EB3-EGFP were imaged over time. Bottom images show z-projections of 25 502 frames of EB3-EGFP. B) Cumulative distribution plots of speed, persistence and comets from 503 DMSO, LCX and HCX-treated cells. Scale $=10 \mu \mathrm{m}$

505 Figure 5. Analysis of glycosaminoglycan chains in conditioned media from Neuro2A cells after 506 xyloside treatment. A) Quantification of CS GAGs present in conditioned media sample. B) CS 507 disaccharides analysis C) Quantification of HS GAGs present in conditioned media sample. D) 508 HS disaccharide analysis. 
510 Figure 6. RNAseq analysis of xyloside-treated Neuro2A cells. Neuro2A cells were treated with

511 the indicated levels of xylosides for $72 \mathrm{~h}$. RNA was extracted and sequenced. A) Volcano plots

512 showing significant changes in gene expression $(>50 \%$ change, $\mathrm{P}<0.5)$ between $\mathrm{HCX}$ and

513 DMSO-treated cells and HCX and LCX-treated cells. B) Venn diagram showing numbers of

514 genes changed with HCX compared to DMSO and LCX treatment. C) Heat map of expressed

515 genes that were changed by xyloside treatment. Color represents deviation from the average

516 expression over all conditions. 

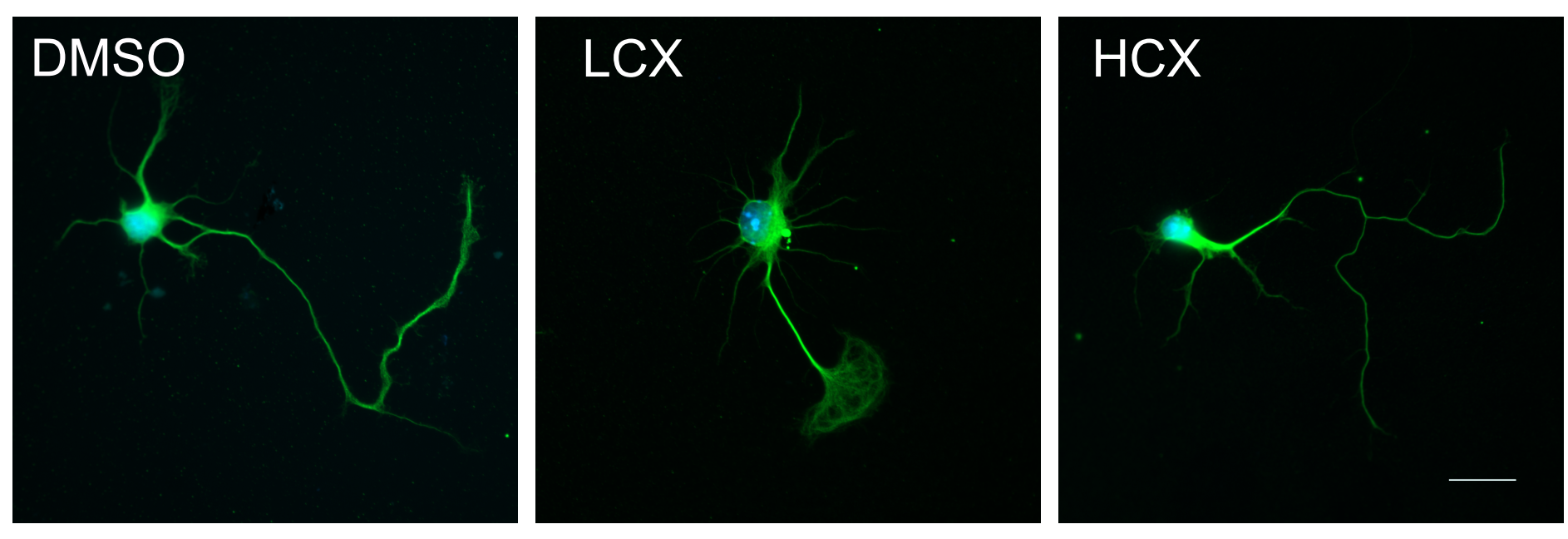

Longest neurite
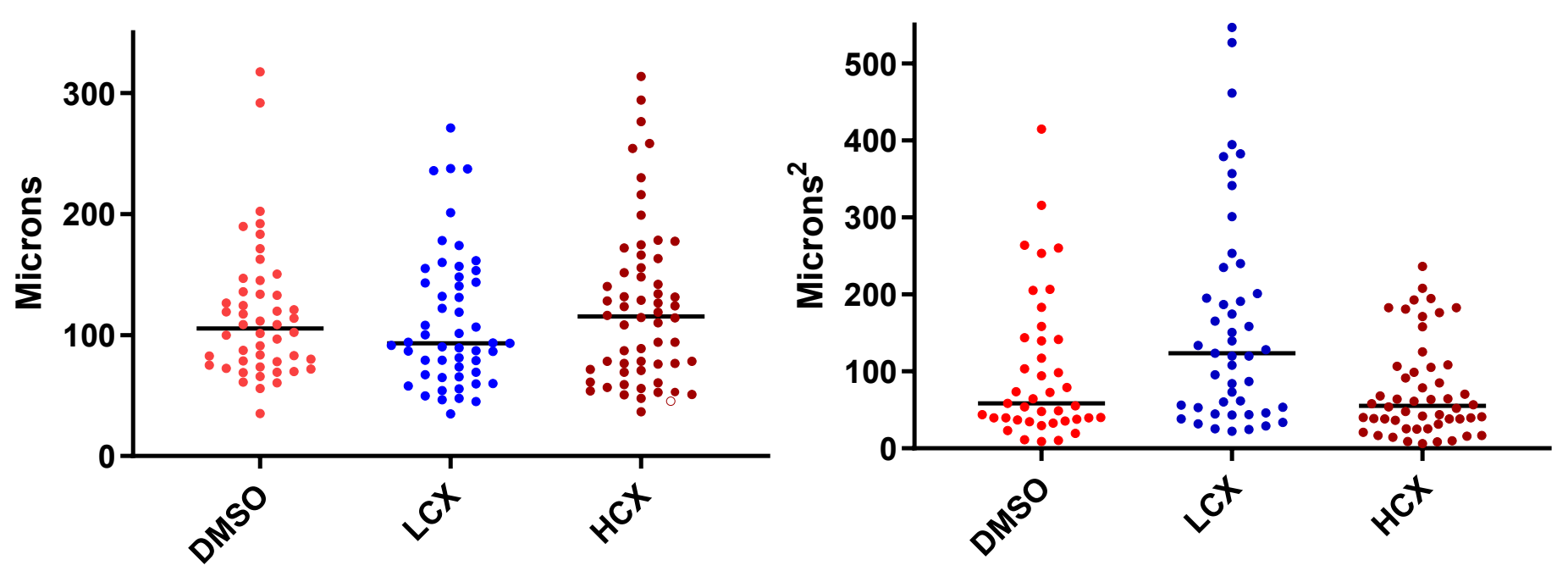
bioRxiv preprint doi: https://doi.org/10.1101/2022.01.31.478500; this version posted January 31, 2022. The copyright holder for this preprint (which was not certified by peer review) is the author/funder. This article is a US Government work. It is not subject to copyright under 17 USC 105 and is also made available for use under a CCO license.
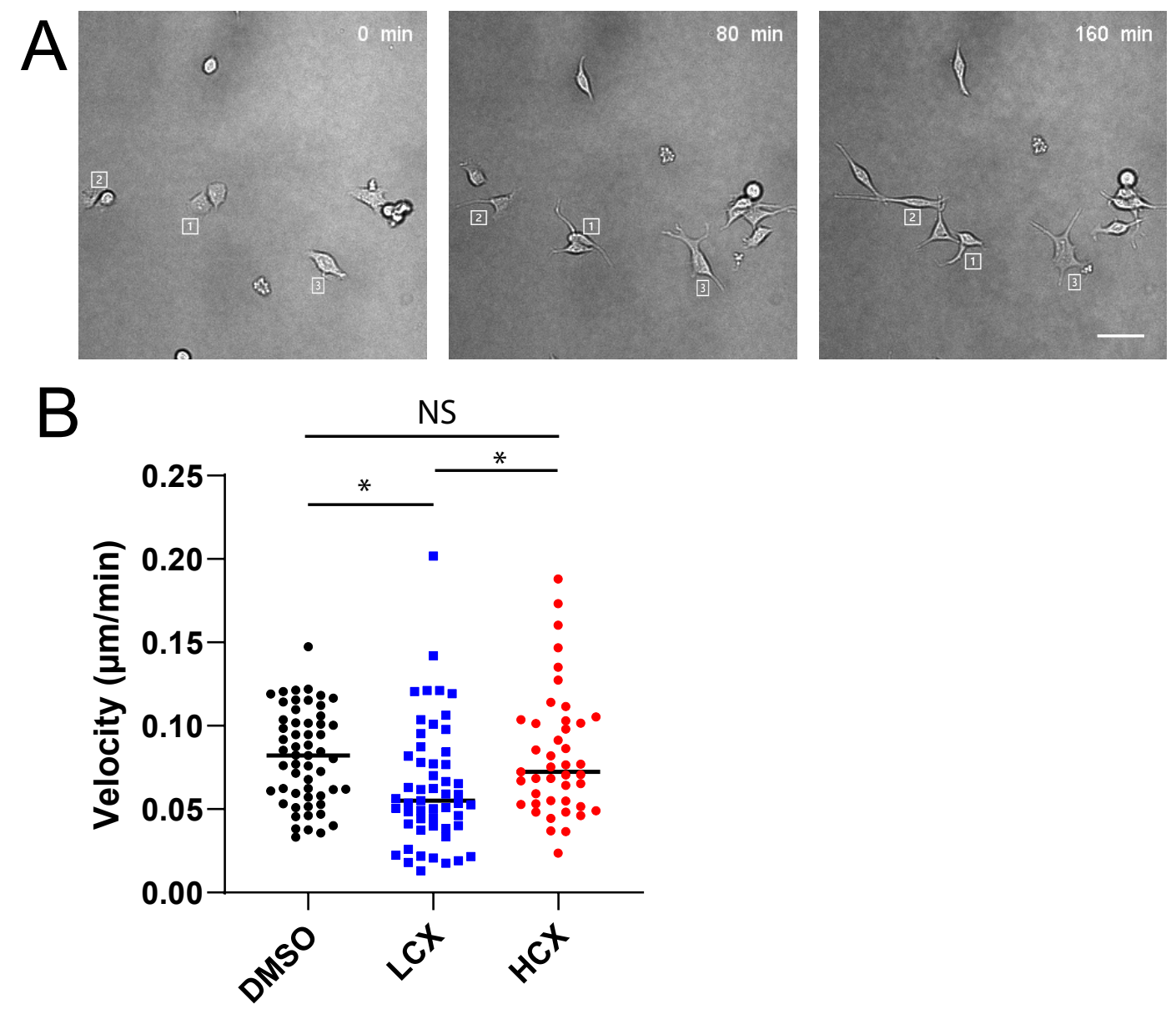
bioRxiv preprint doi: https://doi.org/10.1101/2022.01.31.478500; this version posted January 31, 2022. The copyright holder for this preprint (which was not certified by peer review) is the author/funder. This article is a US Government work. It is not subject to copyright under 17 USC 105 and is also made available for use under a CCO license.

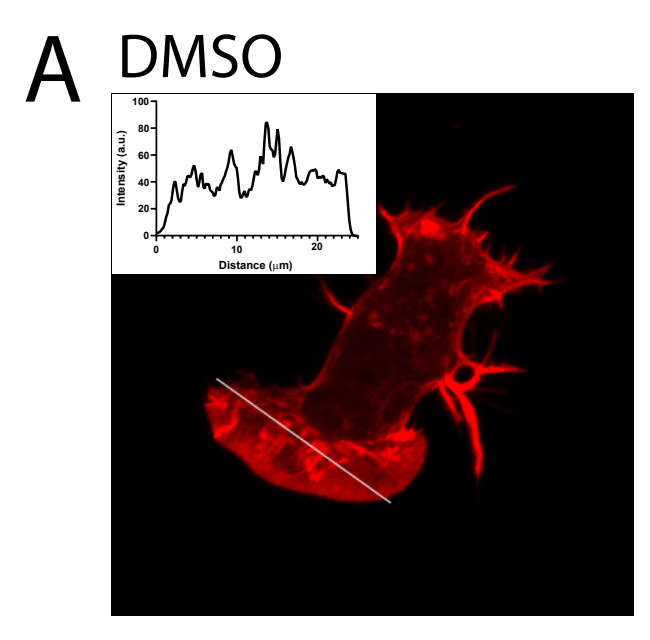

B

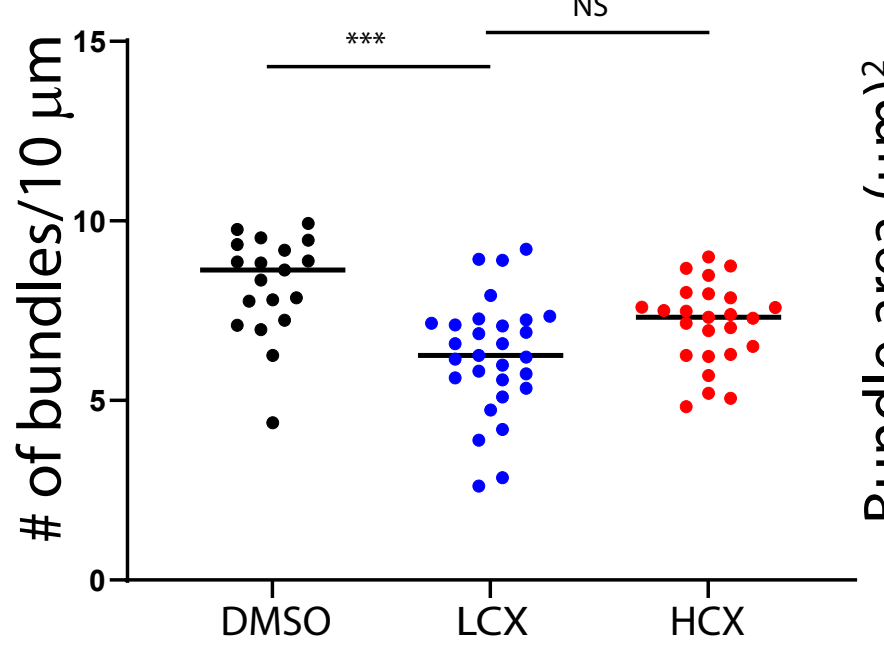

LCX
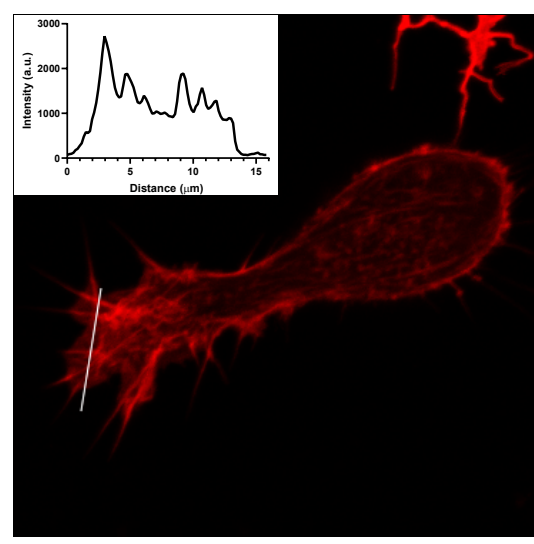

C
HCX
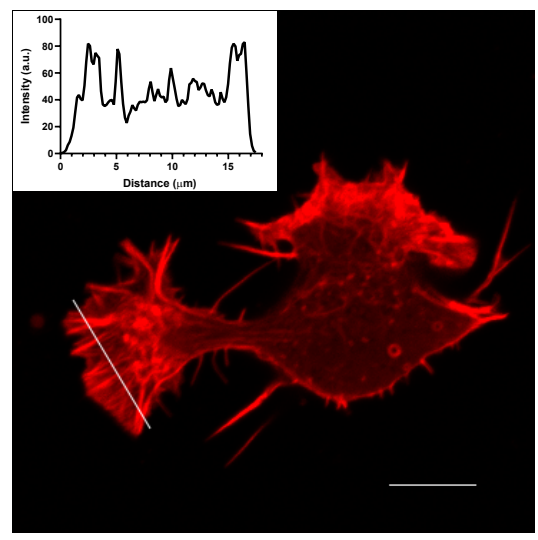

NS
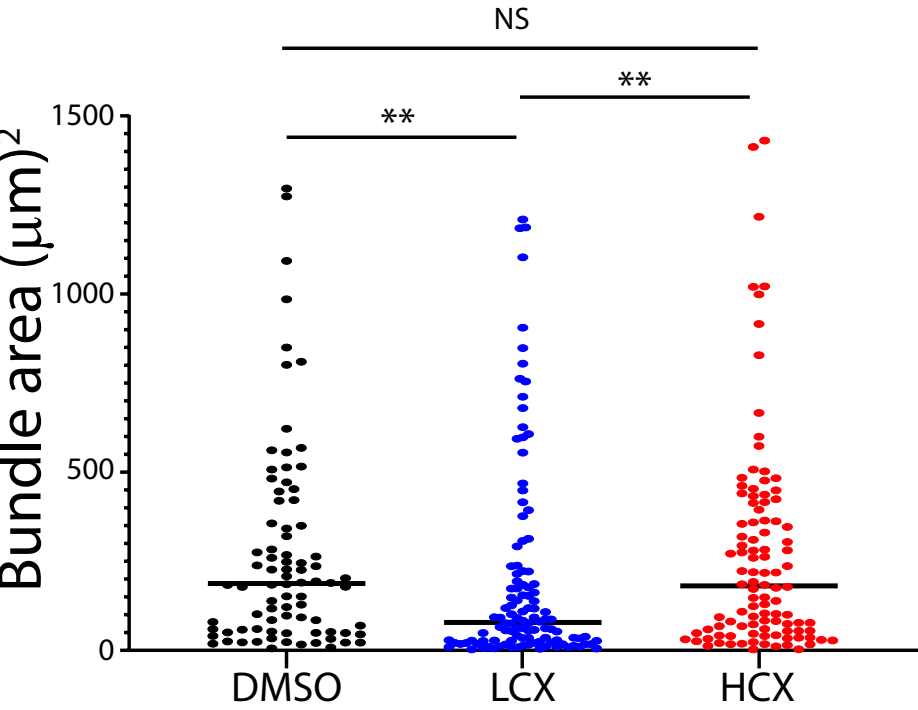
bioRxiv preprint doi: https://doi.org/10.1101/2022.01.31.478500; this version posted January 31, 2022. The copyright holder for this preprint (which was not certified by peer review) is the author/funder. This article is a US Government work. It is not subject to copyright under 17 USC 105 and is also made available for use under a CCO license.
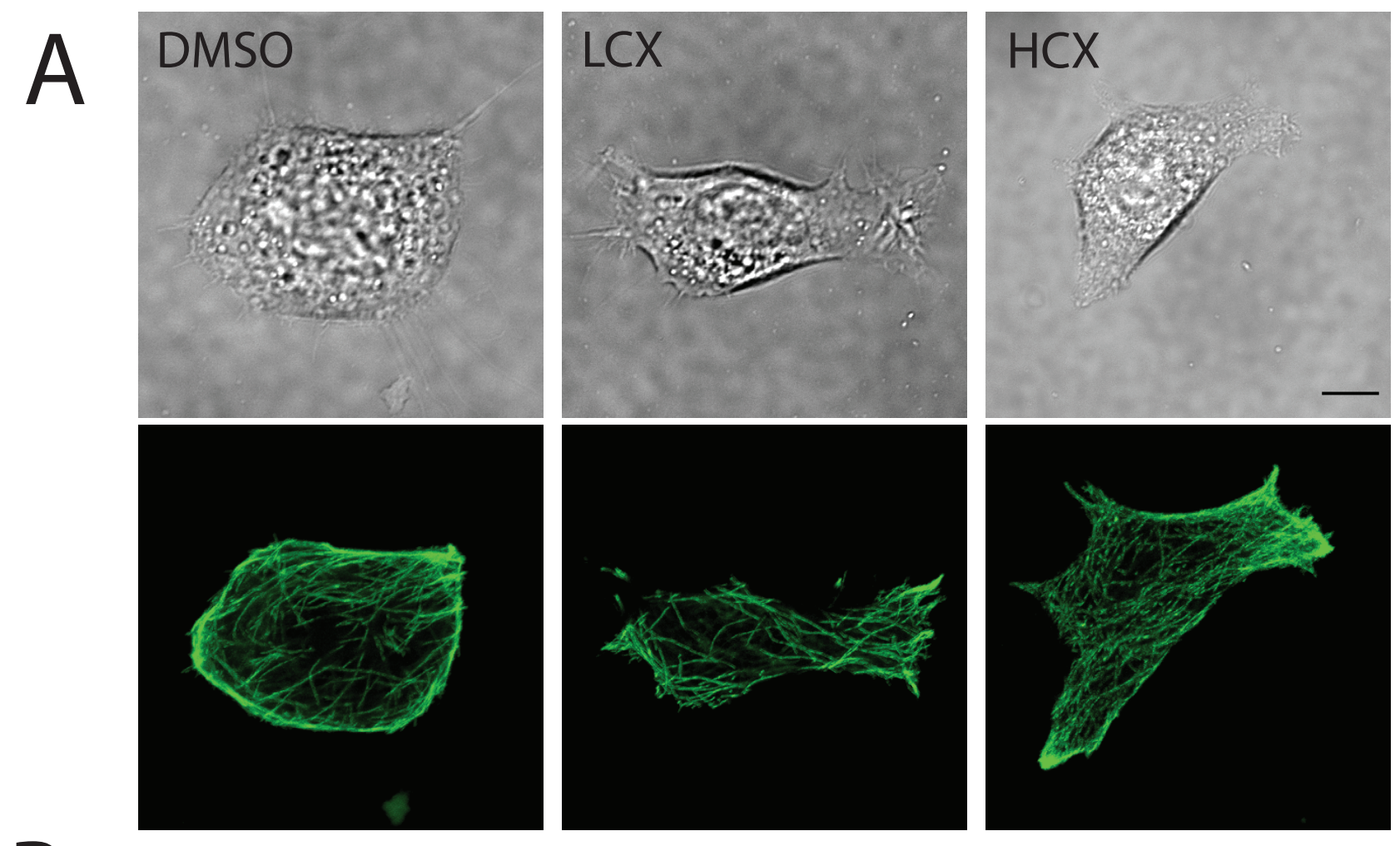

B

Histogram of 200715_Speed

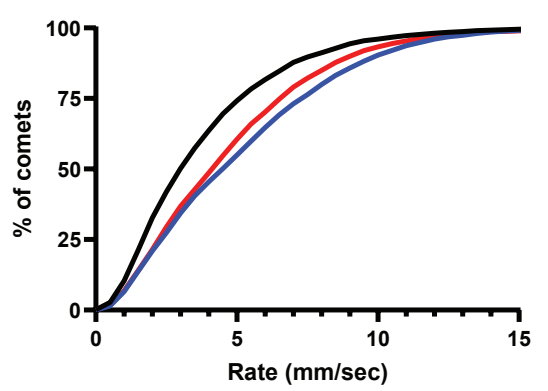

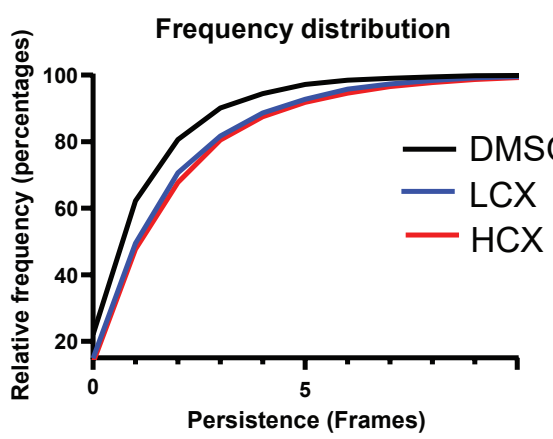

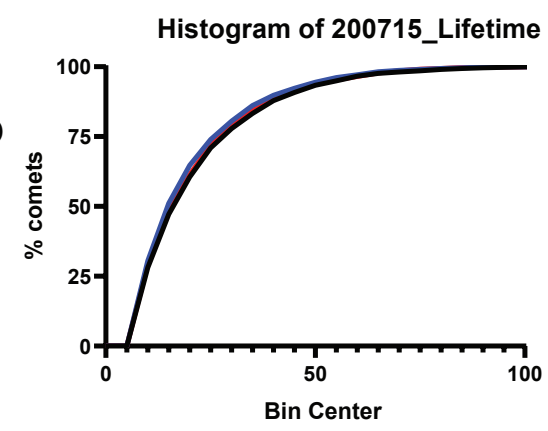




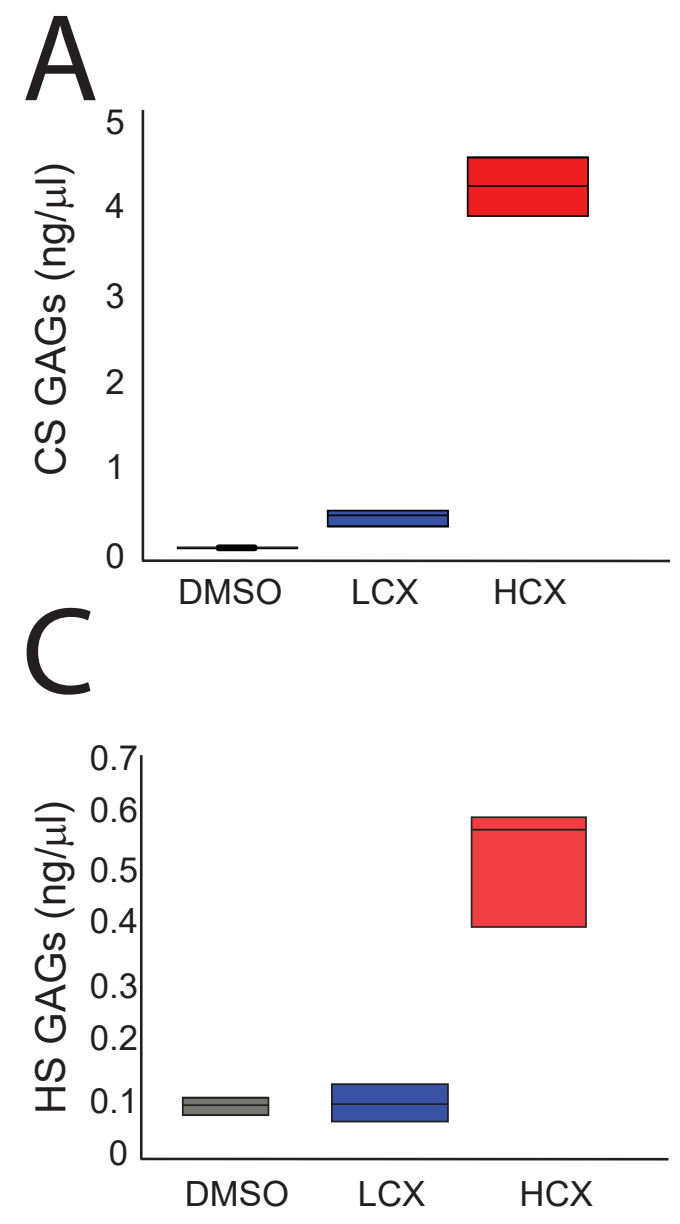

B

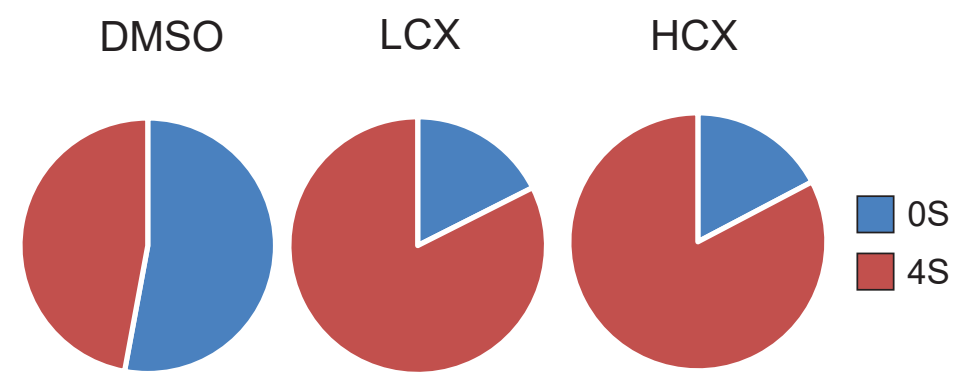

CS GAG Composition

D

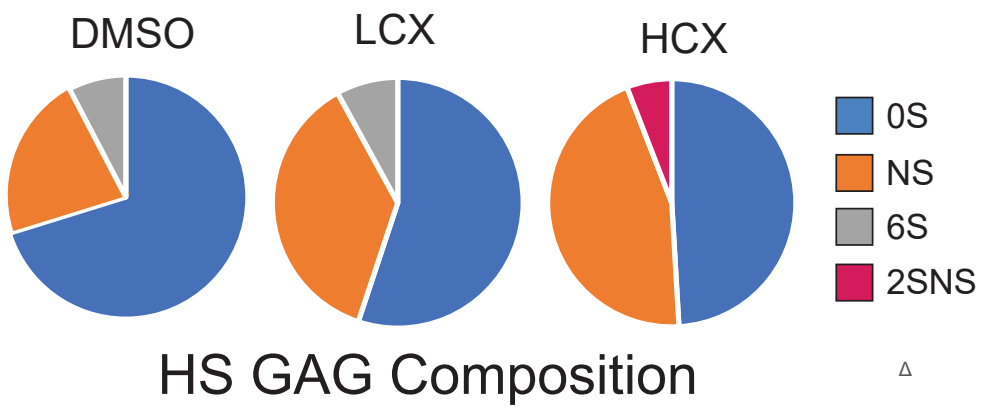



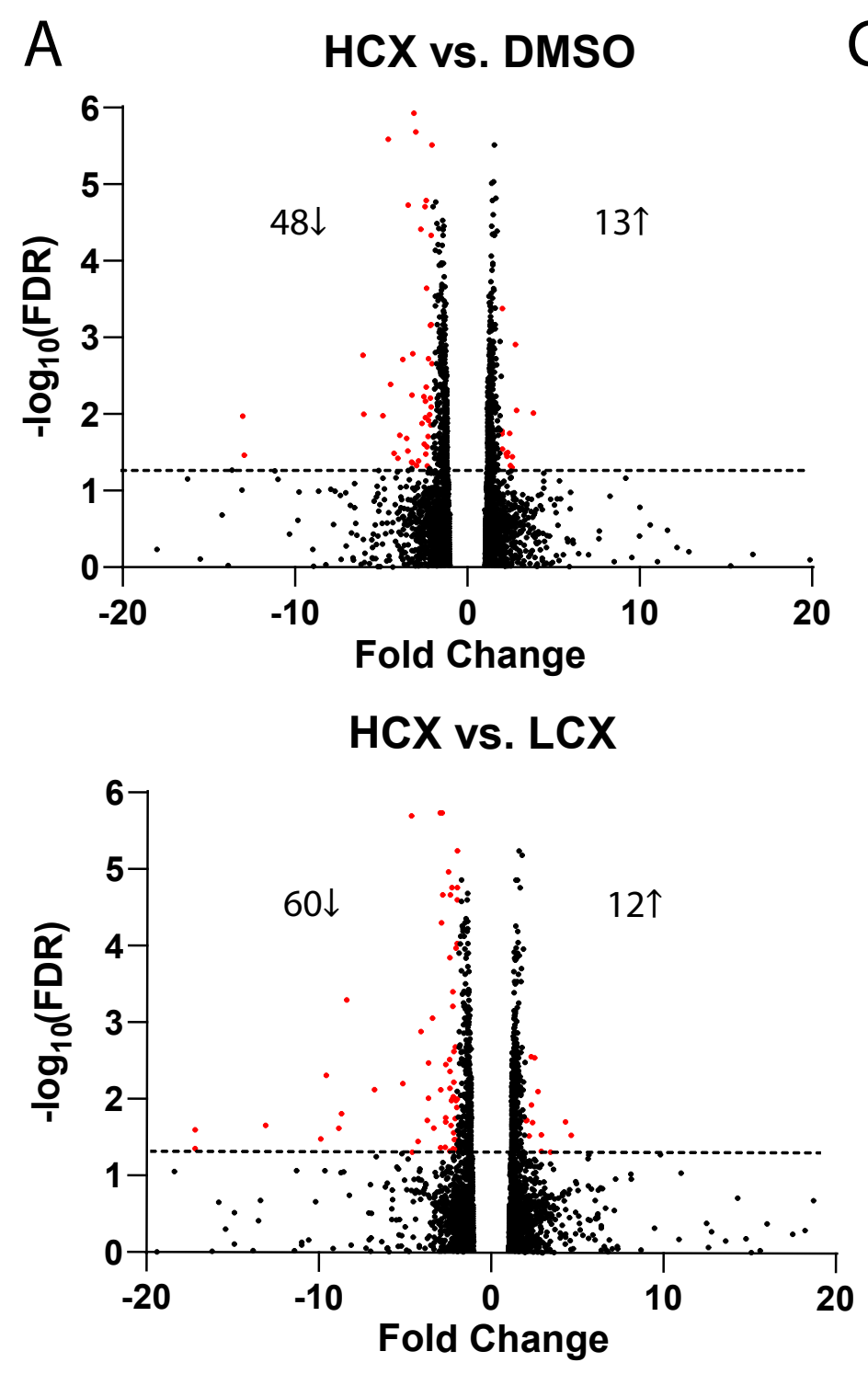

B

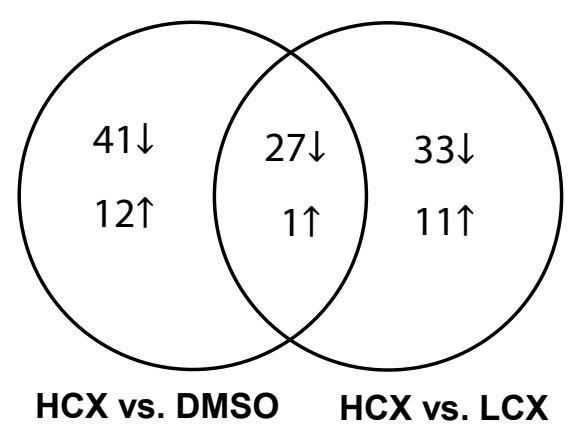

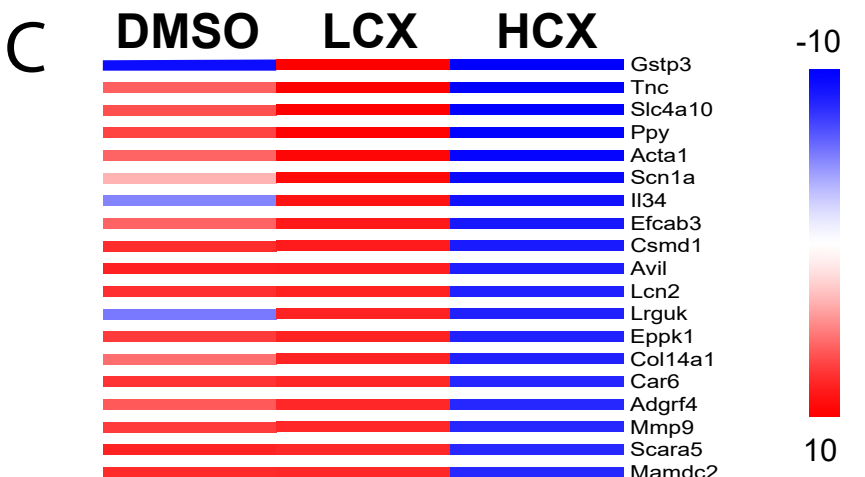


bioRxiv preprint doi: https://doi.org/10.1101/2022.01.31.478500; this version posted January 31, 2022. The copyright holder for this preprint (which was not certified by peer review) is the author/funder. This article is a US Government work. It is not subject to copyright under 17 USC 105 and is also made available for use under a CCO license.
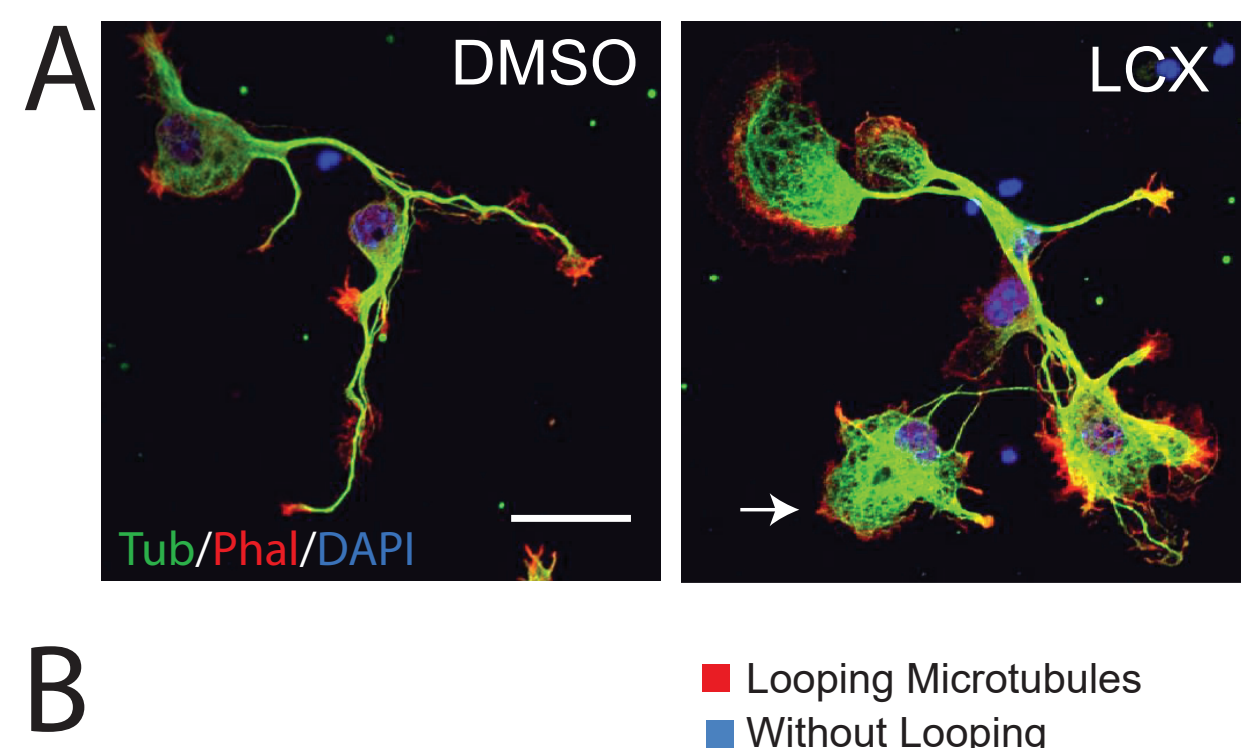

Looping Microtubules

- Without Looping

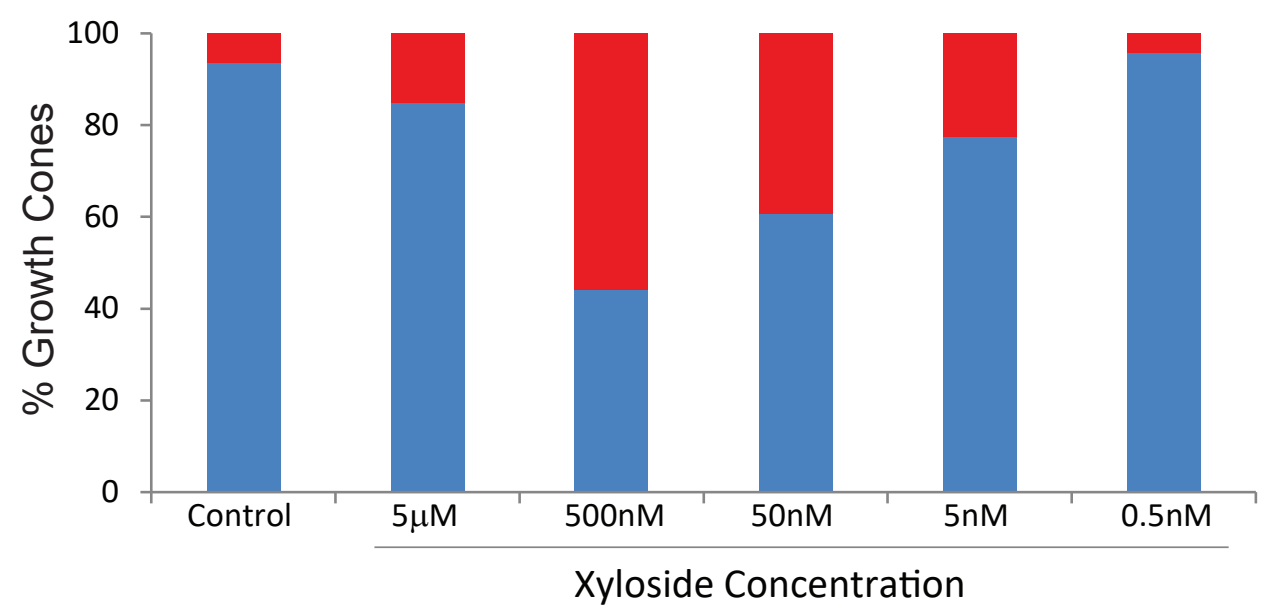


bioRxiv preprint doi: https://doi.org/10.1101/2022 0131.478500; this version posted January 312022. The copyright holder for this preprint

(which was not certified by peer review) is the author/funder. This article is a US Government work. It is not subject to copyright under 17 USC 105 and is also made available for use under a CCO license.

Supp. Figure 1. Microtubule looping in xyloside-treated growth cones. A) Images of hippocampal neurons treated with either DMSO or LCX. LCX-treated neurons have large growth cones with extensive microtubule looping (arrow). B) Dose response curve for xyloside treatment. Percentage of neurons with looped microtubules at the end of the growth cones increased and peaked at 500nM xyloside treatment. 
bioRxiv preprint doi: https://doi.org/10.1101/2022.01.31.478500; this version posted January 31, 2022. The copyright holder for this preprint (which was not certified by peer review) is the author/funder. This article is a US Government work. It is not subject to copyright under 17 USC 105 and is also made available for use under a CCO license.
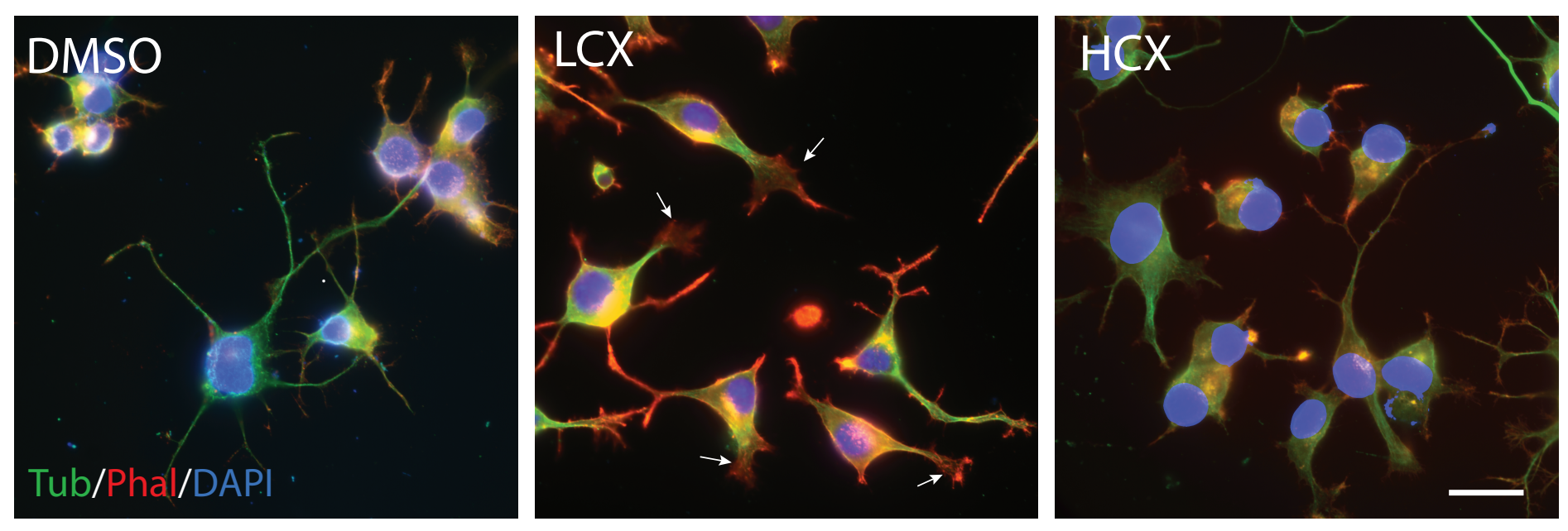
bioRxiv preprint doi: https://doi.org/10.1101/2022 01.31.478500; this version posted January 31,2022. The copyright holder for this preprint

(which was not certified by peer review) is the author/funder. This article is a US Government work. It is not subject to copyright under 17 USC 105 and is also made available for use under a CCO license.

Supp. Fig. 2. Altered Neuro2A morphology in cells treated with LCX or HCX. (Left) DMSOtreated Neuro2A cells show typical morphology with extended processes. (Center) LCX-treated cells show increased levels of phalloidin staining with lamellipodia (arrow). (Right) HCX-treated cells resemble DMSO-treated cells with processes. Scale $=25 \mu \mathrm{m}$. 